\author{
African American Race is Associated with Poorer Outcomes in Heart Failure \\ Patients \\ Kelly L. Wierenga, PhD, RN \\ Case Western Reserve University \\ Rebecca L. Dekker, PhD, RN, APRN University of Kentucky \\ Terry A. Lennie, PhD, RN, FAAN University of Kentucky \\ Misook L. Chung, PhD. RN. University of Kentucky \\ Kathleen Dracup, PhD, RN, FAAN University of California, San Francisco
}

Name and Address for Correspondence:

Kelly L. Wierenga, PhD, RN

Frances Payne Bolton School of Nursing

Case Western Reserve University

10900 Euclid Avenue

Cleveland, Ohio 44106-4904

Fax: 216-368-3542 Telephone: 231-557-0270 Email:

Disclosures: None

Journal Subject Codes : Cardiovascular, Black, Descriptive Quantitative

This is the author's manuscript of the article published in final edited form as:

Wierenga, K. L., Dekker, R. L., Lennie, T. A., Chung, M. L., \& Dracup, K. (2017). African American race is associated with poorer outcomes in heart failure patients. Western journal of nursing research, 39(4), 524-538. https://doi.org/10.1177\%2F0193945916661277 


\begin{abstract}
Health care disparities associated with African American race may influence event-free survival in patients with heart failure (HF). A secondary data analysis included 863 outpatients enrolled in a multicenter HF registry. Cox regression was used to determine whether African American race was associated with shorter HF event-free survival after controlling for covariates. The multivariable-adjusted hazard ratios $(95 \%$ confidence intervals) of older age 1.03 (95\% confidence intervals [CI] 1.01, 1.04), NYHA functional class 1.73 (95\% CI 1.29, 2.31), depressive symptoms 1.05 (95\% CI 1.02, 1.07), and African American race $1.64(95 \%$ CI 1.01, 2.68) were predictors of shorter event-free survival (all $\mathrm{p}<.05$ ). Comparisons showed that NYHA functional class was predictive of shorter event-free survival in Caucasians 1.81 (95\% CI 1.33, 2.46) but not in African Americans 1.24 (95\% CI .40, 3.81). African Americans with HF experienced a disparate risk of shorter event-free survival not explained by a variety of risk factors.
\end{abstract}

Keywords: Health disparities, heart failure, race 


\section{African American Race is Associated with Poorer Outcomes in Heart Failure Patients}

Health outcomes for patients with heart failure (HF) have trended both positively and negatively in the last two decades, depending on which is the outcome of interest. From 1993 to 2006, patients with HF experienced reductions in hospital lengths of stay and mortality, but at the cost of increasing number and frequency of hospitalizations (Bueno et al., 2010). From 2000 to 2010, there were no changes in rates of HF hospitalizations (Go et al., 2013) with one in four (24\%) patients readmitted within 30 days of hospital discharge (Ross et al., 2010).

The HF cost burden is largely tied to unanticipated hospitalizations during the 30 day post-discharge period brought on by disease exacerbations (American Heart Association, 2012). As a major public health concern, HF leads annual health care expenditures in the United States, costing $\$ 39.2$ billion dollars annually while affecting 5.8 million patients (American Heart Association, 2012). One method of capturing the impact of utilization is with event-free survival, or the amount of time to a first negative health event such as emergency department use, hospitalization, or death (Wu et al., 2010). Longer periods of time to a negative health event generally indicate better individual outcomes as well as decreased cost burden (Ross et al., 2010).

There are many known risk factors that can contribute to poor outcomes in patients with HF. Measures of increased disease severity in patients with HF correlate with increased risk for mortality and use of health care services (Karasek, Widimsky, Ostadal, Hrabakova, \& Penicka, 2012). Patients are more likely to experience shorter event-free survival if they are of African American race (Wu et al., 2010), increased age 
(Bagchi, Stewart, McLaughlin, Higgins, \& Croghan, 2011; Karasek et al., 2012;

Saczynski et al., 2009), low income and education (Hawkins, Jhund, McMurray, \&

Capewell, 2012; Roe-Prior, 2007), have high levels of depressive symptoms (Chung,

Lennie, Dekker, Wu, \& Moser, 2011), high levels of anxiety (De Jong et al., 2011), high

levels of stress (Chung et al., 2011), or low levels of adherence (Son, Lee, \& Song, 2011;

Song, 2009; Wu et al., 2010). Researchers have reported individual and grouped

contributions of these risk factors. Despite this research, it is not well understood how

sociodemographic, psychosocial, disease factor, and treatment contributions impact HF

event-free survival when examined together.

Understanding subpopulations is a critical step towards improving outcomes in

patients with HF. This understanding is particularly relevant to African American

patients, as they use more urgent care resources and have rates of HF readmissions far

exceeding those of Caucasians (Menash, Mokdad, Ford, Greenlund, \& Croft, 2005;

Philbin \& DiSalvo, 1998; Roe-Prior, 2007; Wu et al., 2010). The limited evidence

regarding this specific vulnerable population reveals lower rates of adherence and poorer

event-free survival in African American as compared to Caucasian patients with HF (Wu et al., 2010). One study examining the racial disparity of adherence in HF patients found that African American patients have 32\% lower rates of medication adherence compared with Caucasian patients (Wu et al., 2010). The lack of understanding relative to HF outcomes in African Americans highlights a clear gap in the empirical literature. For these reasons it is important that we determine the extent of the disparity in HF event-free survival between African American and Caucasian patients. 
The limited evidence that we have so far suggests that African American patients are experiencing worse event-free survival. The purpose of this study was to validate this claim and seek clarity on the relationship between African American and Caucasian ethnicities and HF event-free survival. Specifically, the aim of this project was to determine whether ethnicity is an independent predictor of HF event-free survival (defined as time to HF hospitalization, emergency department visit for HF, or HF death) among patients with HF, controlling for age, gender, body mass index (BMI), smoking, interventions, New York Heart Association (NYHA) functional class, ejection fraction, and depressive symptoms. A secondary aim of this study was to determine if African Americans with HF have different predictors of HF event-free survival than Caucasians.

\section{Methods}

\section{Data Source}

This study was conducted as a secondary data analysis of the Heart Failure Quality of Life Registry, which combined data from research studies across the United States (see Table 1). Detailed registry procedures and methods are presented in detail elsewhere (Dekker et al., 2014; Dracup et al., 2014; Lee, Lennie, Wu, Biddle, \& Moser, 2014; Moser et al., 2013). Participants were enrolled in both intervention and nonintervention studies capturing event-free survival in patients with $\mathrm{HF}$ along with various covariate and independent variables. All participants provided informed consent and all parent projects were monitored by human subjects review boards.

\section{Sample and Setting}

Data were analyzed from 863 outpatients enrolled in a multicenter HF registry who were followed for a median of 1.9 years (37\% female, $10.5 \%$ African American, 
$64 \pm 13$ years, $38 \%$ NYHA Class III/IV). Patients were eligible if they had a confirmed diagnosis of HF, were English speaking, were living at home and not in an institution, and were patients in a cardiology clinic or had been hospitalized for HF within the previous 12 months. Patients were excluded if they had serious life-threatening comorbidity or severely impaired cognition that would prevent independent self-care. Recruitment took place in California, Indiana, Kentucky, and Nevada.

Participants within the registry data set were enrolled in intervention and nonintervention studies. The purposes and interventions within these projects are detailed elsewhere and an overview presented in Table 1. The presence of an intervention was controlled for in this secondary data analysis.

Participants were eligible for inclusion in this secondary data analysis if they had complete data for variables in the primary analysis. All participants also had complete follow-up event data. Additionally, participants from only the self-identified Caucasian and African American ethnicities were included because there were too few participants in other ethnic groups for analysis.

\section{Measures}

\section{Predictors of shorter HF event-free survival}

Heart failure event-free survival predictors of particular importance are those regarding disease severity, treatment, and other health factors such as comorbidity and psychological distress. Parent studies included a variety of these predictors of poorer HF event-free survival. To maintain power with the limited number of African American participants, predictors for the main analysis were selected to maintain a maximum sample of African American participants. Further narrowing of variables was necessary 
particularly in terms of HF disease characteristics. Disease characteristics of NYHA class and ejection fraction were chosen for final analysis over other characteristics such as etiology. Variables selected for inclusion include age, gender, BMI, smoking, inclusion in an intervention, ejection fraction, NYHA functional class, and depressive symptoms. Additional variables were measured to describe the sample.

Data on demographics, including age, gender, marital status, race and ethnicity were collected for each participant using self-report. Additionally smoking status, comorbid conditions, BMI, current medications, ejection fraction, and cardiac event data were all collected via chart review and interview. NYHA class was determined by patient interview.

As depressive symptoms are a key indicator of poor event-free survival in patients with HF (Chung et al., 2011; Wu et al., 2013), patients included in the study had completed a depressive symptom scale. Depressive symptoms were measured with the Patient Health Questionaire-9 (PHQ-9). The PHQ-9 is a 9-item measure developed based on the 9 criteria for diagnosis of depressive disorders in line with the Diagnostic and Statistical Manual of Mental Disorders (Kroenke \& Spitzer, 2002). This scale presents severity of depressive symptoms from 0-27 with higher numbers representing more severe symptoms. Cut points of 5 indicate mild, 10 moderate, 15 moderately severe, and 20 severe depressive symptoms (Kroenke \& Spitzer, 2002).

\section{Outcome variable}

The outcome variable of HF event-free survival was measured and was calculated as time to the first occurrence of a negative HF health event defined as HF hospitalization, HF emergency department visit, or death from HF causes. Patients were 
called monthly for the first year, and then followed by medical record review for up to 3.5 years to collect data about event-free survival. All self-reported events were verified with hospital records, and all deaths were verified with medical record review or death certificate review. Trained cardiovascular advanced practice research nurses who were blinded to demographics and other variables collected data on event-free survival data. Two principal investigators on the Registry team adjudicated ambiguous events.

\section{Data Analysis}

Demographic variables of gender, age, marital status, education level and clinical variables of depressive symptoms, body mass index (BMI), NYHA functional class, ejection fraction, preservation of systolic function, etiology of HF, smoking status, and months since diagnosis were used to describe the sample. Descriptive examination of variables was completed, including frequency distributions, means, standard deviations, medians, and interquartile ranges, as appropriate to the level of measurement of the variables. Alpha was set at .05.

We used Cox proportional hazards regression modeling to determine whether African American ethnicity was associated with shorter HF event-free survival, controlling for the covariates of age, gender, BMI, smoking, inclusion in an intervention, ejection fraction, NYHA functional class, and depressive symptoms. For the second specific aim, we conducted Cox proportional hazard regression modeling for Caucasian and African American participants separately controlling for the above mentioned covariates.

\section{Results}

\section{Participants}


From the Registry data set, 863 individuals met inclusion criteria for this study. Sample characteristics are outlined in Table 2. Overall, participants were mostly male $(63 \%), 64.1 \pm 12.7$ years of age, $10.5 \%$ were African American, and 38\% were NYHA Class III/IV. The mean PHQ-9 score was $6.7 \pm 6.0$ with good internal validity in the African American sample with Cronbach alpha $=.874$.

African American participants were younger, $\mathrm{M}=57.0 \mathrm{SD}=9.8$ years, compared to Caucasians, $\mathrm{M}=65.0 \mathrm{SD}=12.7$, and were more likely to be smokers $(\mathrm{p}<.001)$. Additional differences noted in this sample were that there was a higher percentage of females among African American participants compared to Caucasian participants $(\mathrm{p}<.001)$, and a lower percentage of married African American participants $(\mathrm{p}<.001)$. The African American participants also had a smaller proportion with ischemic etiology HF compared to Caucasian participants $(\mathrm{p}<.001)$.

Of the patients included in this analysis, $3(0.4 \%)$ died of HF causes, all of these individuals were Caucasian. Patients hospitalized for HF reasons were the most common HF event ( $n=185,21.4 \%)$. Of those hospitalized for HF, 164 were Caucasian and 21 were African American. Eight patients (0.9\%) visited the emergency department for HF reasons over the follow-up period, with all of these individuals also being Caucasian.

\section{Differences in HF Event-Free Survival}

Among the entire sample, age, ethnicity, and depressive symptoms were all predictors of shorter HF event-free survival in multivariable-adjusted hazard ratios $(95 \%$ confidence intervals, all $\mathrm{p}<.05$; See Table 3 ). Hazard ratios after adding ethnicity in block 2 (95\% confidence intervals) indicate the strength of these relationships, with older age increasing the hazard of a negative health event of $1.03(1.01,1.04)$, African 
American ethnicity at $1.64(1.01,2.68)$, higher NYHA functional classification at 1.73 $(1.29,2.31)$, and incrementally increasing depressive symptoms at $1.05(1.02,1.07)$.

Survival curves indicated a shorter HF event-free survival for African American participants (See Figure 1). Importantly, these survival curves account for the controlled covariates (age, gender, BMI, smoking, presence of an intervention, ejection fraction, NYHA functional class, and depressive symptoms). African American participants experienced poorer HF event-free survival at nearly all time points within the curves, an almost immediate substantial downward trend is seen on the survival curve in African American time to their first health event occurs as compared to the curves of Caucasians. These results suggest that African Americans with HF experienced a disparate risk of cardiac events not explained by clinical, demographic or psychological risk factors.

To aid in explaining these differences, a second Cox regression model demonstrates the differences between contributing factors separated by ethnicity. In the Caucasian patients, age, NYHA functional class, and depressive symptoms were all predictors of shorter HF event-free survival in multivariable-adjusted hazard ratios $(95 \%$ confidence intervals, all $\mathrm{p}<.05$ ) (See Table 4). As a comparison, in African American patients, only age and depressive symptoms were predictors of the same outcome. Hazard ratios (95\% confidence intervals) indicate that older age increased the hazard of a negative health event by $1.03(1.01,1.04)$ in Caucasian patients and $1.07(1.02-1.12)$ in African American patients. Incrementally increasing depressive symptoms was at 1.04 $(1.02,1.07)$ in Caucasians and $1.09(1.02-1.18)$ in African American patients. With NYHA functional classification, significance was only found with Caucasians demonstrating hazard ratios at $1.81(1.33,2.46)$. 


\section{Discussion}

The primary finding of this study was that African American patients experienced disparate shorter HF event-free survival rates that were not explained by a host of potential risk factors. Of additional importance is the clear indication that African American patients with HF experience negative health events sooner than Caucasian patients with HF. It is critical that additional attention is drawn to this disparity and potential resolutions be explored.

\section{Risk Factors}

African American patients in this study experienced higher rates of known risk factors of HF than did Caucasian patients. This is primarily that the African American patients were more likely to be smokers $(\mathrm{p}<.001)$. The increased prevalence of smoking in the African American patients did not explain the differences in HF event-free survival. Neither ethnic group demonstrated an increased hazard ratio of poorer HF event-free survival in the presence of smoking.

Body mass index in this study was not significantly different between the African American and Caucasian group, and was not significant in predicting HF event-free survival. In another study of patients with HF, waist circumference and BMI are each examined and show that better outcomes are seen with both higher waist circumference and higher BMI (Clark, Fonarow, \& Horwich, 2011). Our study does not support the obesity paradox that is commonly reported among patients with HF.

\section{Contributors to Poorer Event-Free Survival}

Age and higher levels of depressive symptoms were shown to impact HF eventfree survival in this population. This significance remains when examining Caucasian 
and African American participants separately. The impact of increasing age on decreased HF event-free survival $(\mathrm{p}<0.001)$ in this study is consistent with the literature.

In discussing the variables of impact in HF event-free survival in this study, it is important to consider the impact seen with depression. Higher depressive symptoms are 1.3 times more prevalent in African Americans than in Caucasians (Bromberger, Harlow, Avis, Kravitz, \& Cordal, 2004) and negatively impact adherence (Luyster, Hughes, \& Gunstad, 2009; Song, 2009). In this study we see that depressive symptoms are an independent predictor of decreased HF event-free survival $(\mathrm{p}<0.001)$. The increased prevalence of depressive symptoms in African American patients (Bromberger et al., 2004), paired with the results in this study, indicates that addressing depression is critical.

Although NYHA functional classification was a predictor in the overall model, the comparison model shows that this variable is only significantly related to poorer HF event-free survival in Caucasian participants.

By approaching the known patient contributors to decreased HF event-free survival, care can be focused on these variables and those patients exhibiting multiple risk factors. Changes to care may include utilizing the risk factors identified to target at risk populations and to intervene on the modifiable risk factors. Reviews of risk factors (Giamouzis et al., 2011) in addition to new empirical evidence such as this project can aid in the development of a much needed risk assessment tool for patients with HF (Betihavas et al., 2012). The development of a risk assessment tool would aid clinicians in identifying at risk populations and potentially burdensome modifiable risk factors.

Well known to clinicians is the importance of treating HF directly to decrease HF severity and prevent worsening of the disease. Less evident is the impact of other 
modifiable risk factors on outcomes of HF such as treating depression. Increasing depressive symptoms in this study was a significant contributor to diminishing HF eventfree survival. Other research has found evidence that those patients with depression in remission experience improved cardiovascular outcomes (Jiang et al., 2011). By treating comorbid conditions, particularly depression, and other modifiable risk factors noted in this analysis there may be improvements in HF outcomes. Modifiable risk factors such as prevention and treatment of HF severity and depression need to be a focus of clinicians. There are many non-modifiable risk factors that cannot be directly intervened upon. This study found in particular that older age and African American ethnicity are predictors of poorer HF event free survival. These non-modifiable risk factors can be used to target interventions and resources in these vulnerable populations.

Such a striking disparity in the outcome of African Americans with HF raises the question as to what beyond patient contributors accounts for the negative outcomes. With the increased prevalence of HF risk factors seen in this population unexplained variance in event-free survival, it is important to consider the possibility of social issues and their negative impact in African American patients.

The disparities of African American patients in event-free survival are not unique to HF. A large body of research has demonstrated that African American patients in general have increased challenges accessing and receiving quality healthcare (Institute of Medicine, 2001; Schoenfeld, Tipirneni, Nelson, Carpenter, \& Iwashyna, 2014). Given that we were unable to find any clinical factors that explained the shorter HF event-free survival of African American patients with HF, research is needed to explore non-patient 
contributors to the disparities in health outcomes experienced by this vulnerable population.

\section{Conclusion}

African American race is an important predictor in event-free survival of patients with HF. Correcting the discriminatory gap between Caucasian and African American patients is highly complex. The multifaceted relationship between the population risk factors includes both non-patient as well as patient contributors. These distinct contributions can be approached from an individual and a population perspective. By using the known risk factors of decreased HF event-free survival, resources can be targeted at the most vulnerable individuals. Research should be focused on developing risk assessment tools to identify vulnerable HF patients. Additionally, research is needed to improve interventions specific to the vulnerable population of African American patients with $\mathrm{HF}$ and in addressing the impact of systematic racism on health of vulnerable populations.

\section{Funding Sources}

This project was funded by the NIH, National Institute of Nursing Research, R01 NR008567; NIH, National Heart Lung and Blood Institute, 1R01HL083176; NIH, National Institute of Nursing Research, 1P20NR010679; and training grants from the NIH (National Institute of Nursing Research K23 NR013480 and 1F31 NR014754);

Sigma Theta Tau Alpha Psi; Blue Cross and Blue Shield of Michigan Foundation; and the Jonas Center for Nursing Excellence. 


\section{References}

American Heart Association. (2012). About Heart Failure. Retrieved from http://www.heart.org/HEARTORG/Conditions/HeartFailure/AboutHeartFailure/A bout-Heart-Failure UCM 002044 Article.jsp - .T2OGPczeZD8

Bagchi, A. D., Stewart, K., McLaughlin, C., Higgins, P., \& Croghan, T. (2011). Treatment and Outcomes for Congestive Heart Failure by Race/Ethnicity in TRICARE. Medical Care, 49(5), 489-495. doi:10.1097/MLR.0b013e318207ef87

Betihavas, V., Davidson, P. M., Newton, P. J., Frost, S. A., Macdonald, P. S., \& Stewart, S. (2012). What are the factors in risk prediction models for rehospitalisation for adults with chronic heart failure? Australian Critical Care, 25(1), 31-40. doi:http://dx.doi.org/10.1016/j.aucc.2011.07.004

Bromberger, J. T., Harlow, S., Avis, N., Kravitz, H. M., \& Cordal, A. (2004). Racial/ethnic differences in the prevalence of depressive symptoms among middle-aged women: the Study of Women's Health Across the Nation (SWAN). American Journal of Public Health, 94(8), 1378-1385. doi:10.2105/ajph.94.8.1378

Bueno, H., Ross, J. S., Wang, Y., Chen, J., Vidan, M. T., Normand, S. T., . . Krumholz, H. M. (2010). Trends in length of stay and short-term outcomes among medicare patients hospitalized for heart failure, 1993-2006. JAMA, 303(21), 2141-2147. doi:10.1001/jama.2010.748

Chung, M. L., Lennie, T. A., Dekker, R. L., Wu, J.-R., \& Moser, D. K. (2011). Depressive symptoms and poor social support have a synergistic effect on eventfree survival in patients with heart failure. Heart \& Lung, 40(6), 492-501. doi:10.1016/j.hrtlng.2010.08.001

Clark, A. L., Fonarow, G. C., \& Horwich, T. B. (2011). Waist Circumference, Body Mass Index, and Survival in Systolic Heart Failure: The Obesity Paradox Revisited. Journal of Cardiac Failure, 17(5), 374-380. doi:10.1016/j.cardfail.2011.01.009

De Jong, M. J., Chung, M. L., Wu, J.-R., Riegel, B., Rayens, M. K., \& Moser, D. K. (2011). Linkages between anxiety and outcomes in heart failure. Heart \& Lung, 40(5), 393-404. doi:10.1016/j.hrtlng.2011.02.002

Dekker, R. L., Lennie, T. A., Doering, L. V., Chung, M. L., Wu, J. R., \& Moser, D. K. (2014). Coexisting anxiety and depressive symptoms in patients with heart failure. European Journal of Cardiovascular Nursing, 2014(13), 168-176.

Dracup, K., Moser, D. K., Pelter, M. M., Nesbitt, T. S., Southard, J., Paul, S. M., . . . Cooper, L. S. (2014). Randomized controlled trial to improve self-care in patients with heart failure living in rural areas. Circulation, 130, 256-264.

Giamouzis, G., Kalogeropoulos, A., Georgiopoulou, V., Laskar, S., Smith, A. L., Dunbar, S., . . Butler, J. (2011). Hospitalization Epidemic in Patients With Heart Failure: Risk Factors, Risk Prediction, Knowledge Gaps, and Future Directions. Journal of Cardiac Failure, 17(1), 54-75. doi:http://dx.doi.org/10.1016/j.cardfail.2010.08.010

Go, A. S., Mozaffarian, D., Roger, V. L., Benjamin, E. J., Berry, J. D., Borden, W. B., . . . Turner, M. B. (2013). Heart Disease and Stroke Statistics-2013 Update: A 
Report From the American Heart Association. Circulation, 127(1), e6-e245. doi:10.1161/CIR.0b013e31828124ad

Hawkins, N. M., Jhund, P. S., McMurray, J. J., \& Capewell, S. (2012). Heart failure and socioeconomic status: accumulating evidence of inequality. Eur J Heart Fail, 14(2), 138-146. doi:10.1093/eurjhf/hfr168

Institute of Medicine. (2001). Crossing the Quality Chasm: A New Health System for the 21st Century. Washington D.C.: National Academy Press.

Jiang, W., Krishnan, R., Kuchibhatla, M., Cuffe, M. S., Martsberger, C., Arias, R. M., \& O'Connor, C. M. (2011). Characteristics of Depression Remission and Its Relation With Cardiovascular Outcome Among Patients With Chronic Heart Failure (from the SADHART-CHF Study). The American Journal of Cardiology, 107(4), 545551. doi:http://dx.doi.org/10.1016/i.amjcard.2010.10.013

Karasek, J., Widimsky, P., Ostadal, P., Hrabakova, H., \& Penicka, M. (2012). Acute heart failure registry from high-volume university hospital ED: comparing European and US data. American Journal of Emergency Medicine, 30(5), 695-705. doi:10.1016/j.ajem.2011.03.027

Kroenke, K., \& Spitzer, R. L. (2002). The PHQ-9: A new depression diagnostic and severity measure. Psychiatric Annals, 32(9).

Lee, K. S., Lennie, T. A., Wu, J., Biddle, M. J., \& Moser, D. K. (2014). Depressive symptoms, health-related quality of life, and cardiac event-free survival in patients with heart failure: A mediation analysis. Quality of Life Research, 23(6), 1869-1876.

Luyster, F. S., Hughes, J. W., \& Gunstad, J. (2009). Depression and anxiety symptoms are associated with reduced dietary adherence in heart failure patients treated with an implantable cardioverter defibrillator. Journal of Cardiovascular Nursing, 24(1), 10-17. doi:10.1097/01.jcn.0000317469.63886.24

Menash, G. A., Mokdad, A. H., Ford, E. S., Greenlund, K. J., \& Croft, J. B. (2005). State of disparities in cardiovascular health in the United States. Circulation, 111(10), 1233-1241.

Moser, D. K., Heo, S., Lee, K. S., Hammash, M., Riegel, B., Lennie, T. A., . . Watkins, J. (2013). 'It could be worse... Lot's worse!' Why health-related quality of life is better in older compared with younger individuals with heart failure. Age and Ageing, 626-632.

Philbin, E. F., \& DiSalvo, T. G. (1998). Influence of race and gender on care process, resource use, and hospital-based outcomes in congestive heart failure. The American Journal of Cardiology, 82(1), 76-81.

Roe-Prior, P. (2007). Sociodemographic variables predicting poor post-discharge outcomes for hospitalized elders with heart failure. MEDSURG Nursing, 16(5), 317-321.

Ross, J. S., Chen, J., Lin, Z., Bueno, H., Curtis, J. P., Keenan, P. S., . . Krumholz, H. M. (2010). Recent National Trends in Readmission Rates After Heart Failure Hospitalization. Circulation: Heart Failure, 3(1), 97-103. doi:10.1161/circheartfailure.109.885210

Saczynski, J. S., Darling, C. E., Spencer, F. A., Lessard, D., Gore, J. M., \& Goldberg, R. J. (2009). Clinical features, treatment practices, and hospital and long-term outcomes of older patients hospitalized with decompensated heart failure: the 
Worcester Heart Failure Study. Journal of the American Geriatrics Society, 57(9), 1587-1594. doi:10.1111/j.1532-5415.2009.02407.x

Schoenfeld, A. J., Tipirneni, R., Nelson, J. H., Carpenter, J. E., \& Iwashyna, T. J. (2014). The influence of race and ethnicity on complications and mortality after orthopedic surgery: a systematic review of the literature. Medical Care, 52(9), 842-851. doi:10.1097/MLR.0000000000000177

Son, Y.-J., Lee, Y., \& Song, E. K. (2011). Adherence to a sodium-restricted diet is associated with lower symptom burden and longer cardiac event-free survival in patients with heart failure. Journal of Clinical Nursing, 20(21-22), 3029-3038. doi:10.1111/j.1365-2702.2011.03755.x

Song, E. K. (2009). Adherence to the low-sodium diet plays a role in the interaction between depressive symptoms and prognosis in patients with heart failure. Journal of Cardiovascular Nursing, 24(4), 299-307.

Wu, J., Frazier, S. K., Rayens, M. K., Lennie, T. A., Chung, M. L., \& Moser, D. K. (2013). Medication Adherence, Social Support, and Event-Free Survival in Patients With Heart Failure. Health Psychol, 32(6), 637-646. doi:10.1037/a0028527

Wu, J., Lennie, T. A., De Jong, M. J., Frazier, S. K., Heo, S., Chung, M. L., \& Moser, D. K. (2010). Medication adherence is a mediator of the relationship between ethnicity and event-free survival in patients with heart failure. Journal of Cardiac Failure, 16(2), 142-149. doi:10.1016/j.cardfail.2009.10.017 
Table 1.

Description of Individual Studies from the HF Registry

\begin{tabular}{|c|c|c|}
\hline Study Purpose & Design and Sample & Intervention \\
\hline $\begin{array}{l}\text { Determine the mechanisms } \\
\text { underlying the relationship } \\
\text { between depression, } \\
\text { anxiety, and shorter event- } \\
\text { free survival in patients } \\
\text { with HF (AACN) }\end{array}$ & $\begin{array}{l}\text { Prospective, } \\
\text { longitudinal study } \\
N=(75) \text { outpatients } \\
\text { with HF in Kentucky }\end{array}$ & No intervention \\
\hline $\begin{array}{l}\text { Test the effects of cognitive } \\
\text { behavior therapy and } \\
\text { biofeedback on outcomes } \\
\text { in patients with HF (BFD) }\end{array}$ & $\begin{array}{l}\text { Randomized, } \\
\text { controlled trial } \\
\mathrm{N}=(182) \text { outpatients } \\
\text { with HF in Kentucky }\end{array}$ & $\begin{array}{l}\text { Intervention = } 6 \text { weekly sessions of biofeedback } \\
\text { training and cognitive behavior therapy with a } \\
\text { psychiatric nurse practitioner } \\
\text { Sham Intervention = } 6 \text { weekly talk sessions with a } \\
\text { psychiatric nurse practitioner } \\
\text { Usual care = No visits with the psychiatric nurse } \\
\text { practitioner }\end{array}$ \\
\hline $\begin{array}{l}\text { Determine the relationship } \\
\text { between body mass index } \\
\text { and event-free survival in } \\
\text { outpatients with HF }\end{array}$ & $\begin{array}{l}\text { Prospective, } \\
\text { longitudinal study } \\
\mathrm{N}=(55) \text { outpatients } \\
\text { with HF from Kentucky, } \\
\text { Indiana, and Georgia }\end{array}$ & No intervention \\
\hline $\begin{array}{l}\text { Test the effects of a self- } \\
\text { care education program on } \\
\text { outcomes in rural patients } \\
\text { with HF }\end{array}$ & $\begin{array}{l}\text { Randomized, } \\
\text { controlled trial } \\
\mathrm{N}=(551) \text { outpatients } \\
\text { from Kentucky, } \\
\text { Nevada, and California }\end{array}$ & $\begin{array}{l}\text { There were two intervention groups: Fluid Watchers } \\
\text { LITE and PLUS. Both intervention groups received } \\
\text { counseling about HF and self-monitoring, and } \\
\text { coaching on seeking care. The PLUS group also } \\
\text { received additional counseling, audio tapes and } \\
\text { telephone follow-up. There was also a usual care } \\
\text { group that received usual care from their physician. }\end{array}$ \\
\hline
\end{tabular}

Note. Individual studies are reported in "Coexisting anxiety and depressive symptoms in patients with heart failure" by R. Dekker, et al., (2014) in European Journal of Cardiovascular Nursing, 2014(13), p. 168-176; "Randomized controlled trial to improve self-care in patients with heart failure living in rural areas" by Dracup, et al., (2014) in Circulation, 130, p. 256-264; "Depressive symptoms, health-related quality of life, and cardiac event-free survival in patients with heart failure: A mediation analysis." by Lee, Lennie, Wu, Biddle, \& Moser (2014) in Quality of Life Research, 23(6), p. 1869-1876; and in "'It could be worse... Lot's worse!' Why health-related quality of life is better in older compared with younger individuals with heart failure" by Moser et al., (2013) in Age and Ageing, p. 626-632. 
Table 2.

Participant Characteristics by Ethnicity

\begin{tabular}{|c|c|c|c|c|}
\hline Characteristic & $\begin{array}{l}\text { Overall } \\
\text { sample } \\
\mathbf{N}=863\end{array}$ & $\begin{array}{c}\text { Caucasian } \\
n=772\end{array}$ & $\begin{array}{c}\text { African } \\
\text { American } \\
n=91\end{array}$ & $\begin{array}{c}p \\
\text { value }\end{array}$ \\
\hline Female, \% & $\begin{array}{c}n=319 \\
37.0 \%\end{array}$ & $\begin{array}{c}n=265 \\
34.6 \%\end{array}$ & $\begin{array}{l}n=54 \\
59.3 \%\end{array}$ & $<.001$ \\
\hline Age & $64.1 \pm 12.7$ & $65.0 \pm 12.7$ & $57.0 \pm 9.8$ & $<.001$ \\
\hline Married, \% & $\begin{array}{c}n=479 \\
55.5 \%\end{array}$ & $\begin{array}{c}n=449 \\
58.2 \%\end{array}$ & $\begin{array}{l}\mathrm{n}=30 \\
33.0 \%\end{array}$ & $<.001$ \\
\hline Depression PHQ-9 & $6.7 \pm 6.0$ & $6.74 \pm 6.0$ & $6.4 \pm 6.3$ & .609 \\
\hline Body Mass Index & $31.8 \pm 8.2$ & $31.3 \pm 8.0$ & $34.7 \pm 8.9$ & .144 \\
\hline NYHA functional class, $\%$ & & & & .208 \\
\hline Class I & $\begin{array}{l}n=81 \\
9.4 \%\end{array}$ & $\begin{array}{l}n=77 \\
10.0 \%\end{array}$ & $\begin{array}{l}n=4 \\
4.4 \%\end{array}$ & \\
\hline Class II & $\begin{array}{c}n=451 \\
52.3 \%\end{array}$ & $\begin{array}{c}n=399 \\
51.7 \%\end{array}$ & $\begin{array}{l}n=52 \\
57.1 \%\end{array}$ & \\
\hline Class III & $\begin{array}{c}n=292 \\
33.8 \%\end{array}$ & $\begin{array}{c}n=259 \\
33.5 \%\end{array}$ & $\begin{array}{l}n=33 \\
36.3 \%\end{array}$ & \\
\hline Class IV & $\begin{array}{c}n=39 \\
4.5 \%\end{array}$ & $\begin{array}{c}n=37 \\
4.8 \%\end{array}$ & $\begin{array}{l}\mathrm{n}=2 \\
2.2 \%\end{array}$ & \\
\hline Ejection fraction (\%) & $\begin{array}{c}\mathrm{N}=835 \\
38.1 \pm 15.1\end{array}$ & $38.3 \pm 15.2$ & $36.2 \pm 13.9$ & .685 \\
\hline $\begin{array}{l}\text { Non-preserved systolic function } \\
\text { (Ejection fraction }<40 \% \text { ) }\end{array}$ & $\begin{array}{l}n=515 \\
59.7 \%\end{array}$ & $\begin{array}{c}n=464 \\
60.1 \%\end{array}$ & $\begin{array}{l}n=51 \\
56.0 \%\end{array}$ & .498 \\
\hline Ischemic HF etiology, \% & $48.1 \%$ & $50.6 \%$ & $26.4 \%$ & $<.001$ \\
\hline Education level & & & & .117 \\
\hline Less than High School & $\begin{array}{c}n=161 \\
18.7 \%\end{array}$ & $\begin{array}{c}n=140 \\
18.1 \%\end{array}$ & $\begin{array}{l}n=21 \\
23.3 \%\end{array}$ & \\
\hline High School graduate & $\begin{array}{c}n=354 \\
41.0 \%\end{array}$ & $\begin{array}{c}n=326 \\
42.2 \%\end{array}$ & $\begin{array}{l}n=28 \\
31.1 \%\end{array}$ & \\
\hline Some college or more & $\begin{array}{c}n=347 \\
40.3 \%\end{array}$ & $\begin{array}{c}\mathrm{n}=306 \\
39.6 \%\end{array}$ & $\begin{array}{l}n=41 \\
45.6 \%\end{array}$ & \\
\hline Current smoker, \% & $\begin{array}{c}n=128 \\
14.8 \%\end{array}$ & $\begin{array}{c}n=100 \\
13.0 \%\end{array}$ & $\begin{array}{l}n=28 \\
31.0 \%\end{array}$ & $<.001$ \\
\hline
\end{tabular}

Note. PHQ-9 = Patient Health Questionnaire-9; NYHA = New York Heart Association; HF = Heart Failure 
Table 3.

Cox Regression Model for the Prediction of HF Event-Free Survival

\begin{tabular}{llccc}
\hline Block & \multicolumn{1}{c}{ Variable } & Exp $(\boldsymbol{\beta})$ & $95 \%$ Cl & $p$ value \\
\hline \multirow{2}{*}{ Age } & 1.03 & $1.01-1.04$ & $<.001$ \\
& Female & 1.02 & $.75-1.39$ & .889 \\
& BMI & .99 & $.97-1.01$ & .514 \\
& Smoker & 1.23 & $.80-1.89$ & .338 \\
& Intervention & .76 & $.57-1.01$ & .057 \\
& LVEF<40 & 1.24 & $.91-1.69$ & .182 \\
& NYHA Class III/IV & 1.73 & $1.29-2.31$ & $<.001$ \\
& PHQ-9 Depression & 1.05 & $1.02-1.07$ & $<.001$ \\
& & & & .046 \\
\hline
\end{tabular}

Note. BMI = Body mass index; LVEF $<40$ = Left Ventricular Ejection Fraction less than $40 \%$; NYHA = New York Heart Association; PHQ-9 = Patient Health Questionnaire-9 
Table 4.

Cox Regression Model for the Prediction of Event-Free Survival by Ethnicity

\begin{tabular}{|c|c|c|c|c|c|c|}
\hline \multirow[t]{2}{*}{ Variable } & \multicolumn{3}{|c|}{ Caucasian Patients } & \multicolumn{3}{|c|}{ African American Patients } \\
\hline & $\operatorname{Exp}(\beta)$ & $95 \% \mathrm{Cl}$ & p value & $\operatorname{Exp}(\beta)$ & $95 \% \mathrm{Cl}$ & p value \\
\hline Age & 1.03 & $1.01-1.04$ & .001 & 1.07 & $1.02-1.12$ & .007 \\
\hline Female & 1.08 & $.78-1.49$ & .632 & .57 & $.20-1.63$ & .292 \\
\hline BMI & .99 & $.97-1.02$ & .557 & .99 & $.93-1.04$ & .606 \\
\hline Smoker & 1.14 & $.70-1.85$ & .590 & 2.25 & $.80-6.33$ & .124 \\
\hline Intervention & .80 & $.59-1.08$ & .142 & .56 & $.22-1.43$ & .226 \\
\hline LVEF $<40$ & 1.21 & $.87-1.68$ & .265 & 1.18 & $.39-3.60$ & .770 \\
\hline NYHA Class III/IV & 1.81 & $1.33-2.46$ & $<.001$ & 1.24 & $.40-3.81$ & .711 \\
\hline PHQ-9 Depression & 1.04 & $1.02-1.07$ & .001 & 1.09 & $1.02-1.18$ & .018 \\
\hline
\end{tabular}

Note. BMI = Body mass index; LVEF $<40$ = Left Ventricular Ejection Fraction less than 40\%; NYHA = New York Heart Association; PHQ-9 = Patient Health Questionnaire-9 
Figure 1. Survival Curves of African American and Caucasian Patients with HF

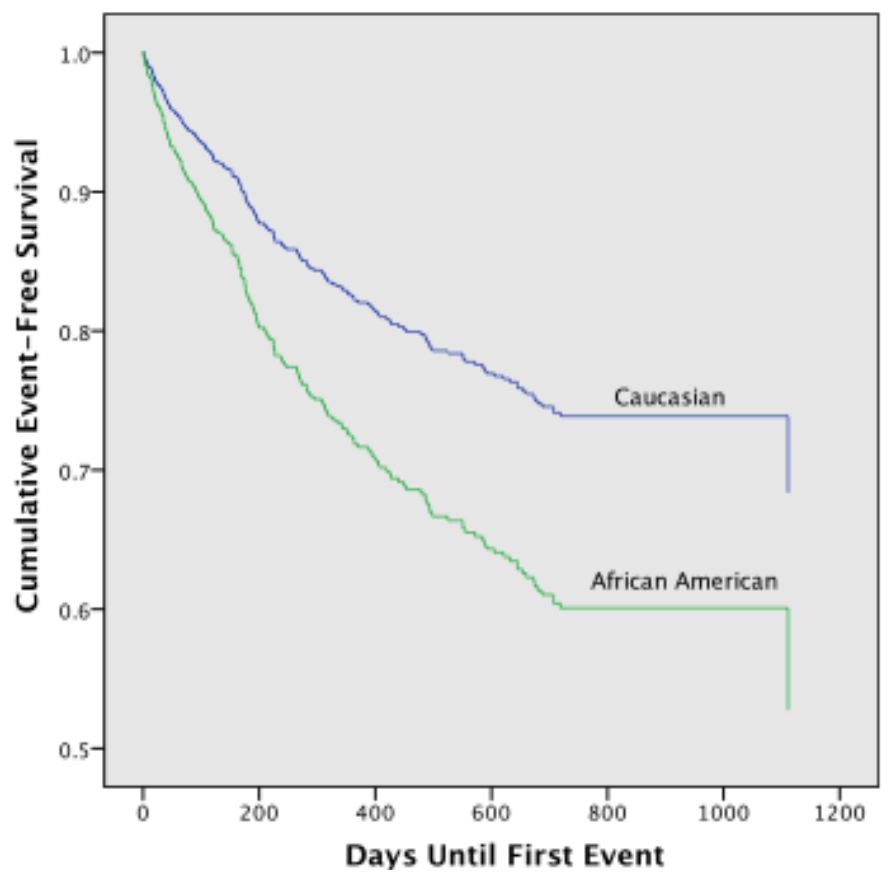

Survival curve indicates the time to the first occurrence of a negative HF health event defined as HF hospitalization, HF emergency department visit, or death from HF causes; HF, Heart Failure. 